\title{
Using an Online Image Analysis Technique to Characterize Sucrose Crystal Morphology during a Crystallization Run
}

\author{
A. Ferreira, ${ }^{+, \neq}$N. Faria, ${ }^{\S}$ F. Rocha, ${ }^{*, \neq}$ and J.A. Teixeira ${ }^{\dagger}$ \\ ${ }^{\dagger}$ IBB-Institute for Biotechnology and Bioengineering, Centre of Biological Engineering, Universidade do Minho, Campus de Gualtar, \\ 4710-057 Braga, Portugal \\ ${ }^{\ddagger}$ LEPAE-Laboratory for Process, Environmental and Energy Engineering, Departamento de Engenharia Química, \\ Faculdade de Engenharia, Universidade do Porto, Rua Dr. Roberto Frias s/n, 4200-465 Porto, Portugal \\ ${ }^{\S}$ BIOTEMPO-Consultoria em Biotecnologia, Lda, Avepark-Zona Industrial da Granda, Apartado 4152, 4806-909 Caldas das Taipas, \\ Portugal
}

\begin{abstract}
The morphological forms and habits of crystals and agglomeration are important properties on crystallization processes. Online techniques for realtime measurement of these properties are mandatory for a better comprehension of crystal growth phenomenon. The present paper presents and describes a new online method to determine the complexity level of a crystal or a population of crystals during a crystallization process. An image analysis technique is combined with discriminant factorial analysis leading to results that allow the computation of the complexity of crystals through the parameter agglomeration degree of crystals. With this methodology, it has been possible to distinguish online and automatically among three different classes of crystals according to their complexity. It further describes the application of such methodology on the study of $\mathrm{CaCl}_{2}, \mathrm{D}$-fructose, and D-glucose influence on the crystallization of sucrose, namely, on crystal size, morphology, and complexity. The effect of supersaturation, growth rate, and impurity concentration on the type, amount, and complexity level of the agglomerates was determined at different temperatures. The combination of image analysis and kinetic results allowed to understand better the crystallization phenomena in the presence and absence of impurities. The image analysis results suggest the possible application of this tool for process control, optimizing, by this way, laboratory and industrial crystallizers.
\end{abstract}

\section{INTRODUCTION}

The impurities effect on crystal growth has been investigated over the years. A great deal of interest in this field is well attested in Sangwal's work. ${ }^{1}$ Originating from raw materials and sometimes from production processes, the impurities affect not only the manufacturing process but also the crystallization kinetics. Some impurities act on the properties of the solutions while others act on the crystals surface, changing their morphology or habit. This morphology change is an important property that affects not only the downstream processing and handling but also the end-use functional properties. Crystal habit is closely associated with filterability, flowability, and compaction behavior among other properties. A sudden change in crystal habit may suggest the appearance of a new polymorph or the presence of trace impurities. Agglomeration may lead to profound changes in final product quality, as well as entrapment of unacceptable levels of occluded solvent, causing difficulties in washing and drying. ${ }^{2}$

On the other hand, the impurity affinity for a specific crystal surface can be useful for crystal morphology changes. The tailormade additives have obtained great importance on crystal growth. They interact in specific ways with selected faces of crystalline materials, thereby inhibiting the growth of preselected faces, and not changing or changing slightly the growth of the other faces. Consequently, a specific crystal morphology is obtained. The additive molecules can lower the growth rate either by physically blocking the layers or by rendering kinks ineffective by adsorbing at them. Thus, the effects of additives on the morphology of growing surfaces of crystals may be distinguished in accordance with the operative mechanism of adsorption. $^{3}$

Concerning the sucrose crystallization along its fundamental and commercial importance, the effects of common syrup impurities (invert sugar, dextran, raffinose, salts, acids, and color) and additives on the growth kinetics and morphology have been extensively studied, in order to improve the product quality. D-Fructose and D-glucose influence on sucrose crystallization are, mainly, focused on crystal morphology change. ${ }^{4-7}$ Crystals grown in the presence of D-glucose are more elongated that the ones grown in the presence of $\mathrm{D}$-fructose. In what concerns their influence on crystal growth rate, a decrease was observed when an equimolar mixture of $\mathrm{D}$-fructose and D-glucose (invert sugar) was used. ${ }^{8-14}$ Inorganic impurities such as $\mathrm{CaCl}_{2}$ decrease the crystal growth rate and sucrose solubility, changing, by this way, the crystallization process. ${ }^{9,15}$ As far as we know, information about the $\mathrm{CaCl}_{2}$ influence on crystal habit is not available.

Beyond the impurity type and concentration, the crystal morphology can be affected by different parameters such as supersaturation, growth rate, temperature, etc. Thus, it is useful, for a correct interpretation of the crystallization process, to have a technique for online monitoring of the crystalline solids. Currently, the only methods that are capable of distinguishing the

\footnotetext{
Received: July 23, 2010

Accepted: March 24, 2011

Revised: March 22, 2011

Published: March 24, 2011
} 


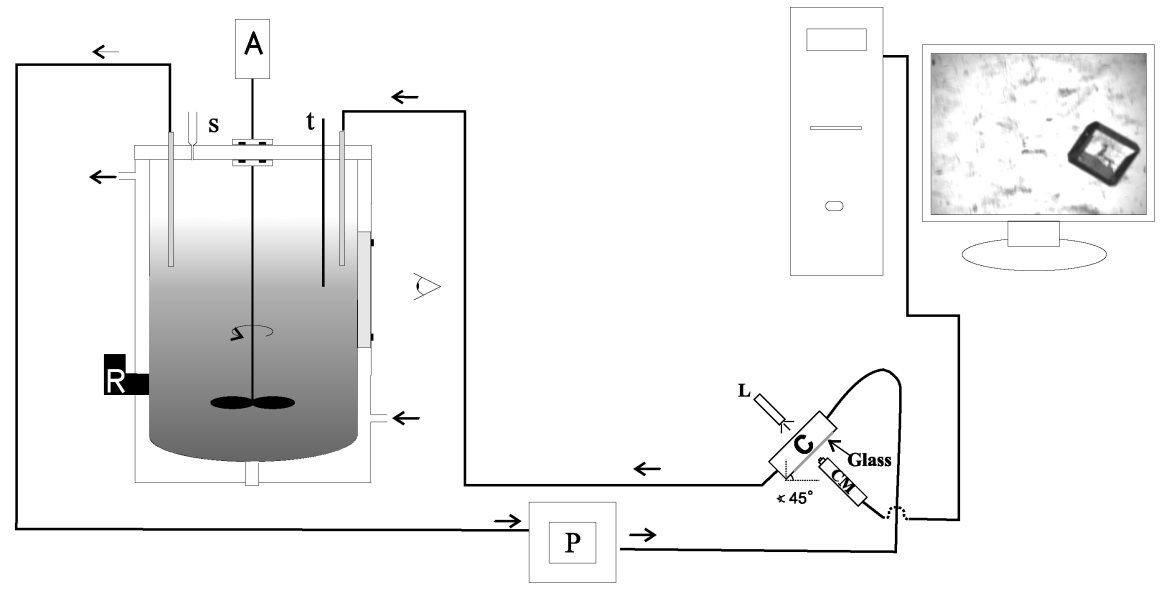

(a)

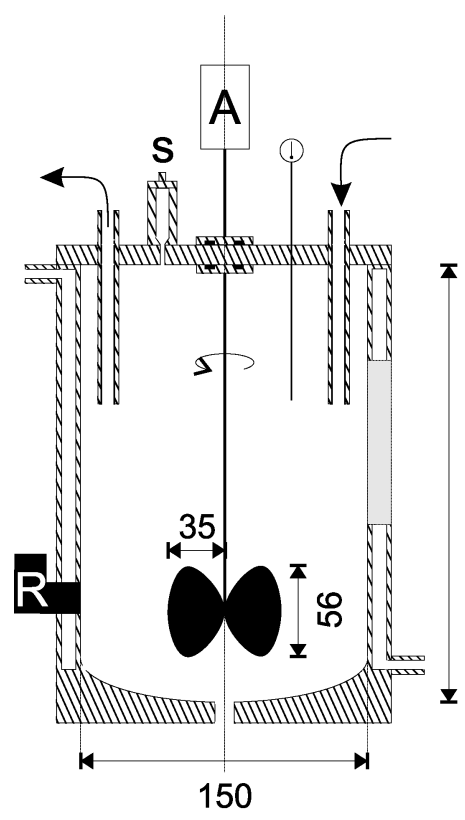

(b)

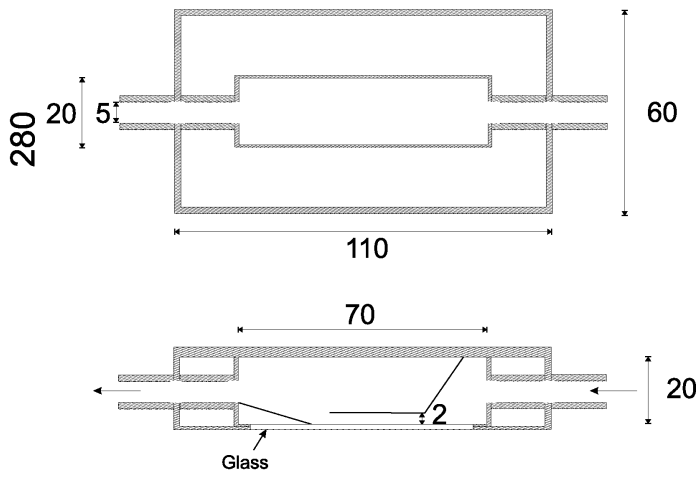

(c)

Figure 1. Experimental apparatus: (a) A, agitator; C, image analysis cell; CM, video camera; L, light source; $t$, thermocouple; s, seed vessel; $\mathrm{P}$, peristaltic pump; R, refractometer; (b) design schematic of the batch crystallizer; (c) design schematic of the image analysis cell. All dimensions in mm.
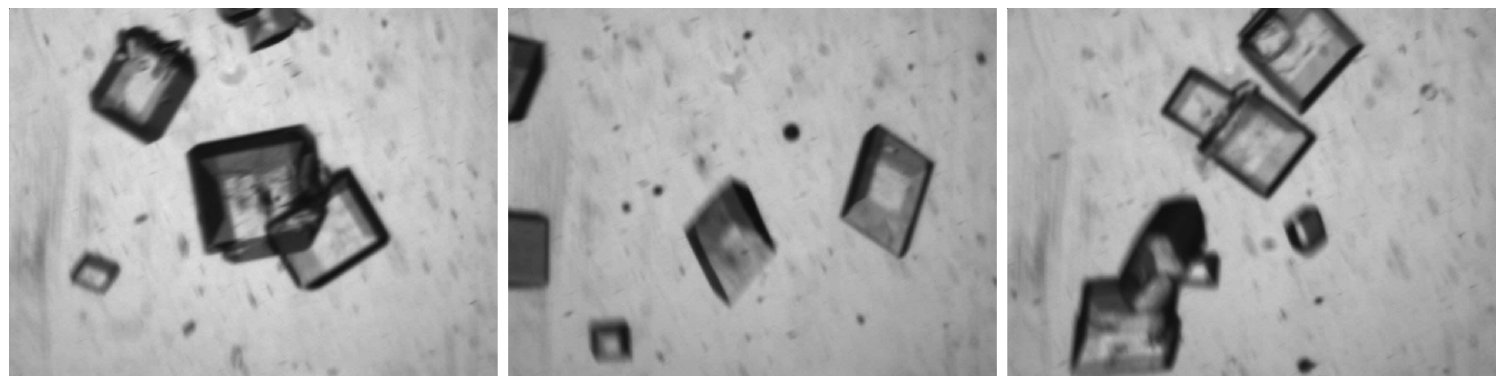

Figure 2. Sequence of images obtained from an image analysis cell.

different crystal dimensions and thus generating appropriate shape factors are the ones based on image analysis techniques. Therefore, in order to obtain online the size and shape of the crystals during the crystallization process, the image analysis technique combined with discriminant factorial analysis was used in the present work. This methodology, has proved to be very effective in off-line quantification of sucrose crystal size and morphology distributions. ${ }^{14,16,17}$ A similar approach was done by 


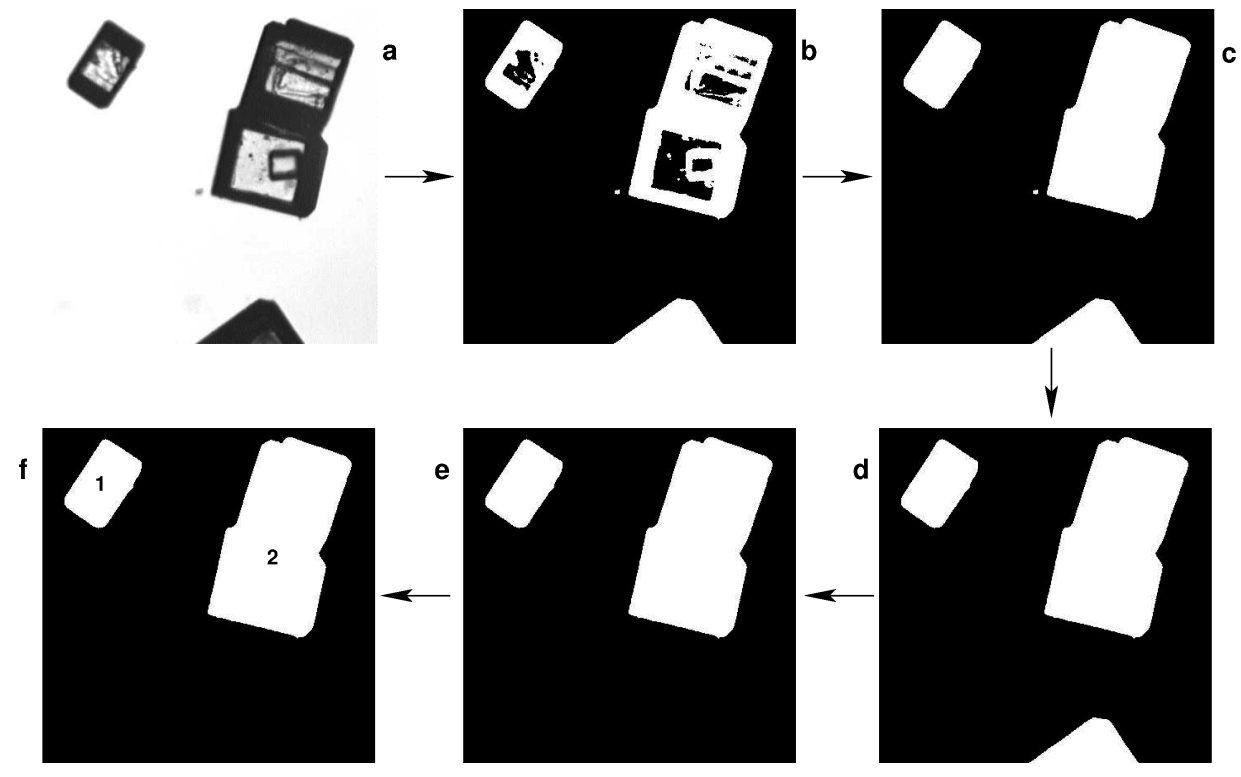

Figure 3. Sequence of operations performed on the images before numerical descriptors extraction. Reprinted with permission from ref 14, copyright 2003, Elsevier.

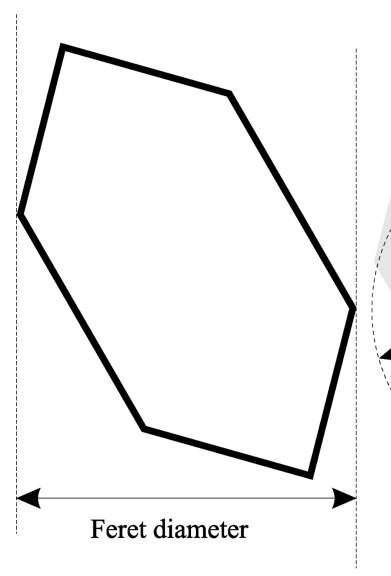

(a)

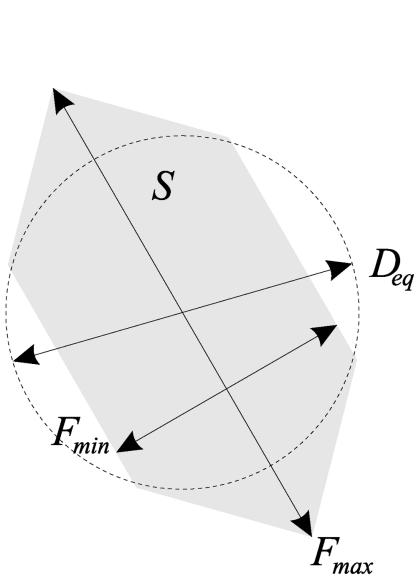

(b)

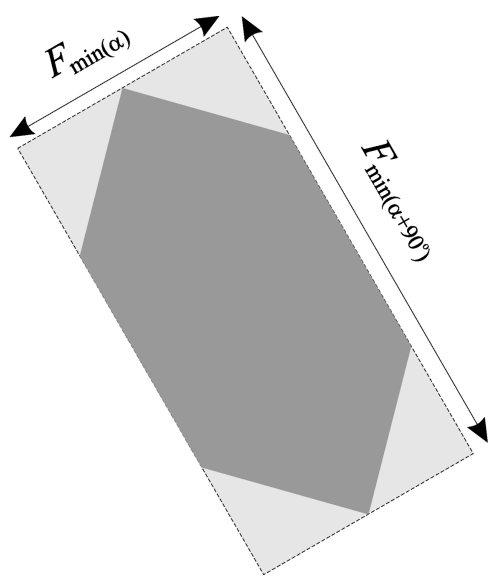

(c)

Figure 4. Image analysis parameters. Feret diameters (a); equivalent diameter (b); $S_{\text {box }}$ (c).

Ferreira et al. ${ }^{18}$ to study the $\mathrm{MgCl}_{2}$ influence on $\mathrm{NaCl}$ crystal morphology. Lionnet ${ }^{19}$ used image analysis to measure crystals growth rates, and Monnier et al. ${ }^{20}$ modeled a bach cooling crystallization of adipic acid, on the basis of the crystal size distribution obtained by off-line image processing. In all these works, the image analysis technique proved to be very useful; however, because the analysis needs to be done outside the crystallizer, several errors can be associated, specially in what concerns the sample collection. The availability of in situ video camera systems offers the opportunity for real-time monitoring and control of the shape and size of crystals. However, online images taken in crystallizer are particulary challenging to analyze because of out-of-focus and overlapping particles and uneven background intensity. Calderon De Anda et al. ${ }^{21}$ presented a multiscale Canny method to segment in situ images of various background pixel intensity resulting from the light effect and temporal changes of hydrodynamics within the crystallizer. The same authors ${ }^{22}$ employed the previous method to segment in situ crystal images and boundary Fourier transform to characterize crystal habit. They monitored successfully the polymorphic transformation process of L-glutamic acid. Martins et al. ${ }^{23}$ used the image analysis technique to measure online the crystal mean size during a boiling run. Nevertheless, the applicability of this method was limited to small crystal contents (up to 10\%) because of image complexity increasing.

In present work, the image analysis technique was applied to sucrose crystallization as an online method to determine, beyond the crystal size, the complexity level of a crystal or a population of crystals. In order to solve the problems mentioned by Calderon De Anda et al. ${ }^{21}$ and Martins et al., ${ }^{23}$ specially associated to the angle of the incident light, the existence of various planes of crystal flow, and the crystal content, a new image analysis cell was developed. By this way, most of the problems related with sample collection were solved and image complexity was reduced. $\mathrm{CaCl}_{2}$, D-fructose, and D-glucose were used as impurities, and their influence on growth rate, crystal morphology, and agglomeration degree at different temperatures $\left(25,35\right.$, and $\left.50^{\circ} \mathrm{C}\right)$ was studied. 


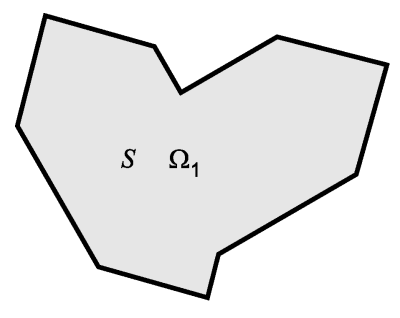

Crystal

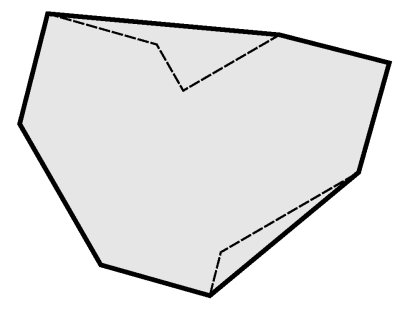

Convex bounding polygon

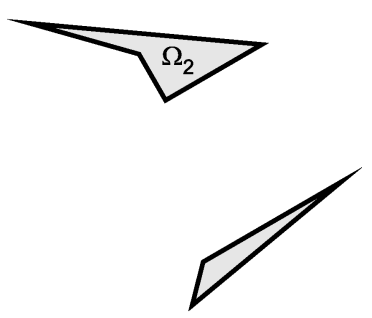

Concavities

Figure 5. Visual meaning of $\Omega_{1}$ and $\Omega_{2}$.

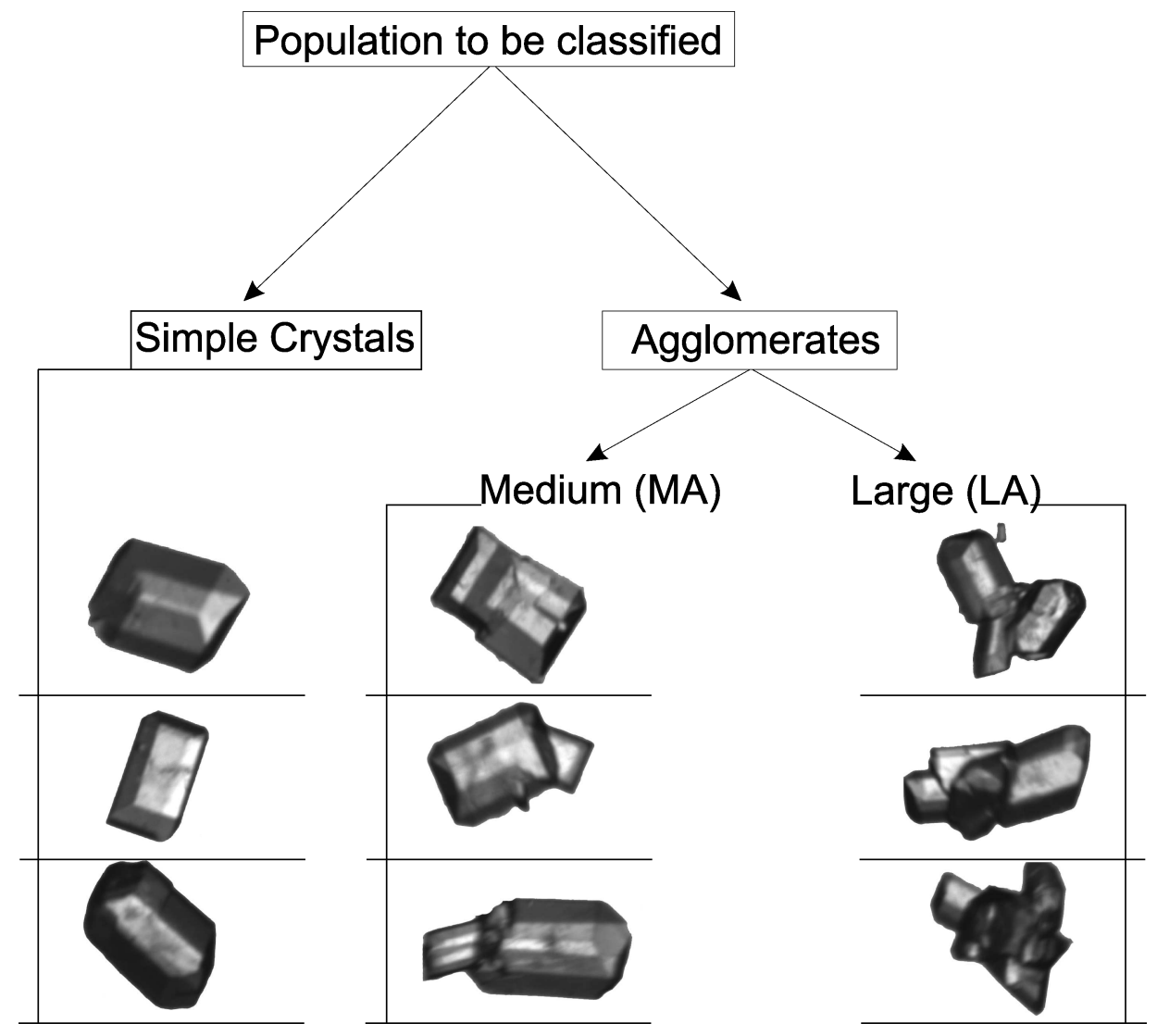

Figure 6. Classification tree for sucrose crystals.

The present study follows the challenges and future developments reported in Yu et al. ${ }^{2}$ According to the authors, advances in online sensors are mandatory to improve the understanding of the crystallization process, thereby enabling more efficient and cost-effective process design and control.

\section{EXPERIMENTAL SECTION}

Experimental Setup. Experiments were carried out in a laboratory-scale $4 \mathrm{~L}$ jacketed and mechanically stirred batch crystallizer (Figure 1). The stirring speed was set at $350 \mathrm{rpm}$, assuring a very homogeneous suspension. Experiments were performed at constant temperature $\left(25,35\right.$, and $\left.50{ }^{\circ} \mathrm{C}\right)$, controlled by a thermostatic bath. $\mathrm{CaCl}_{2}$, D-fructose, and D-glucose were used as impurities in the present work.
Solutions were prepared at $65{ }^{\circ} \mathrm{C}$ by dissolving refinery white sugar (99.95\%, RAR, Portugal) and impurity in ultrapure water, with a resistivity of $18.3 \mathrm{M} \Omega \mathrm{cm}$, obtained through a deionized process (EASYpure RF, Barnstead). Supersaturation was obtained by cooling down the solution to the working temperature. To reach the working temperature, the system takes about $3 \mathrm{~h}$.

Once the temperature was stable, an accurate mass of seed crystals (about $16 \mathrm{~g}$ ) with a mean size of $413 \mu \mathrm{m}$, measured using a laser sizer (Coulter LS 230), was introduced into the crystallizer. The crystals were allowed to grow, leaving the sucrose concentration to decrease until near the saturation. Information about the amount of the dissolved dry solid was taken continuously by an online refractometer (Schmidt+Haensch iPR2).

The crystallized mass was continuously calculated from the variation of the sucrose concentration. On the basis of this information, it was possible to calculate the crystal growth 


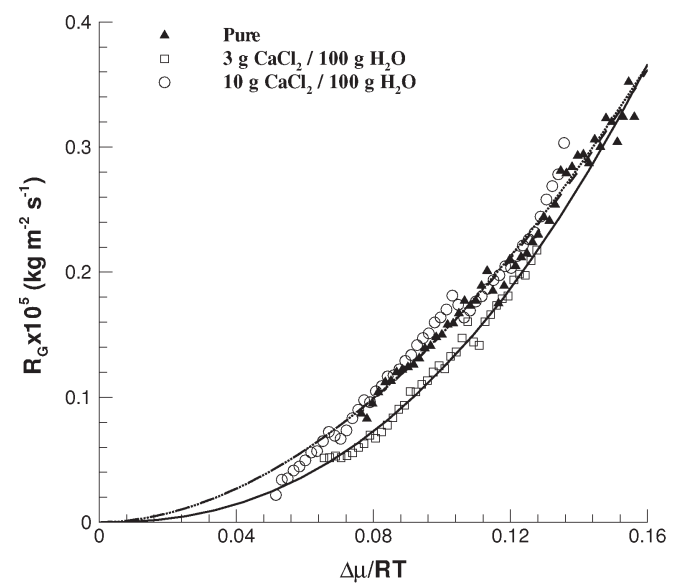

(a)

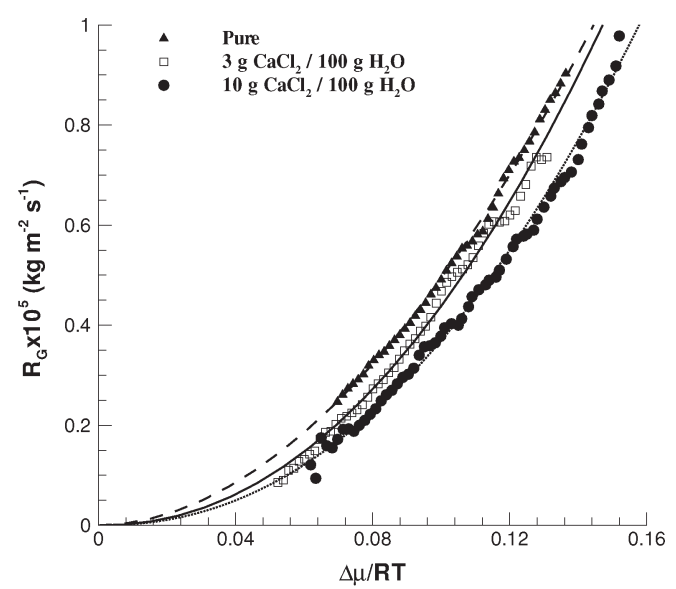

(b)

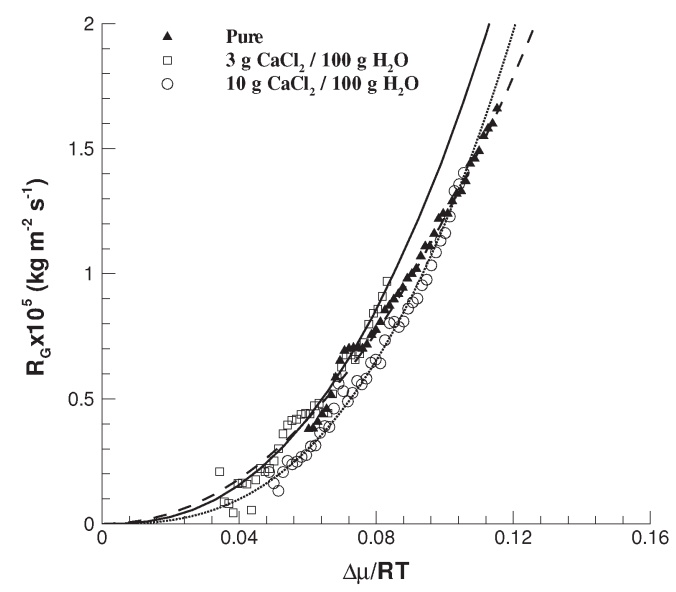

(c)

Figure 7. Growth rates of sucrose in pure mother liquors and in ternary solutions with $\mathrm{CaCl}_{2}$ at $25^{\circ} \mathrm{C}(\mathrm{a}), 35^{\circ} \mathrm{C}(\mathrm{b})$, and $50{ }^{\circ} \mathrm{C}(\mathrm{c})$.

kinetics. $^{24,25}$ In a given period $\Delta t$, the average crystal growth rate $\left(R_{\mathrm{g}}\right)$, at which the mass of crystals $(m)$ increases from $m_{\mathrm{t}}$ to $m_{\mathrm{t}+\Delta \mathrm{t}}$, is given by

$$
R_{\mathrm{g}}=3 \frac{\left(\rho_{\mathrm{c}} \alpha\right)^{2 / 3}}{N^{1 / 3} \beta} \frac{\Delta m^{1 / 3}}{\Delta t}
$$

where $\rho_{\mathrm{c}}$ is the sucrose density $\left(1580.5 \mathrm{~kg} \mathrm{~m}^{-3}\right)$ and $\alpha$ and $\beta$ are the volume and surface shape factors of sucrose crystals, which take the values 0.64 and 4.52 , respectively. The number of crystals, $N$, is given by the ratio between the initial mass of crystals, $m_{0}$, and the mass of a single crystal with a mean size $\left(L_{0}\right)$ of $413 \mu \mathrm{m}:{ }^{26,27}$

$$
N=\frac{m_{0}}{0.64 \rho_{c} L_{0}^{3}}
$$

The number of crystals inside crystallizer is assumed to be constant during the experiments, as significant crystal breakage or agglomeration is not admitted to occur. ${ }^{24}$ The measured growth rates were correlated with the thermodynamic driving force of crystallization $((\Delta \mu) /(\mathrm{RT}))$, according to:

$$
R_{\mathrm{g}}=k_{\mathrm{G}}\left(\frac{\Delta \mu}{R T}\right)^{\mathrm{g}}
$$

Table 1. Parameters Obtained for the Growth Empirical Curves (eq 3) for the System Sucrose $/ \mathrm{H}_{2} \mathrm{O} / \mathrm{CaCl}_{2}{ }^{a}$

\begin{tabular}{cccc}
$T\left({ }^{\circ} \mathrm{C}\right)$ & $C_{\text {imp }}\left(\mathrm{g} / 100 \mathrm{~g} \mathrm{H}_{2} \mathrm{O}\right)$ & $k_{\mathrm{G}} \times 10^{4}$ & $g$ \\
25 & 0 & 1.12 & 1.87 \\
& 3 & 2.85 & 2.37 \\
& 10 & 1.15 & 1.88 \\
& 0 & 4.11 & 1.92 \\
& 3 & 8.08 & 2.27 \\
50 & 10 & 5.64 & 2.18 \\
& 0 & 18.87 & 2.18 \\
& 3 & 108.37 & 2.81 \\
& 10 & 63.19 & 2.72 \\
${ }^{a} k_{\mathrm{G}}$ is presented in $\mathrm{kg} \mathrm{m}^{-2} \mathrm{~s}^{-1}$. & & \\
\hline
\end{tabular}

where $k_{\mathrm{G}}$ is the growth rate constant and $g$ is the overall growth rate order. The thermodynamic driving force of crystallization $((\Delta \mu) /(\mathrm{RT}))$ was expressed as:

$$
\frac{\Delta \mu}{R T}=\left(\ln \frac{\gamma_{\mathrm{i}} x_{\mathrm{i}}}{\gamma_{\mathrm{i}}^{\mathrm{sat}} x_{\mathrm{i}}^{\mathrm{sat}}}\right)
$$




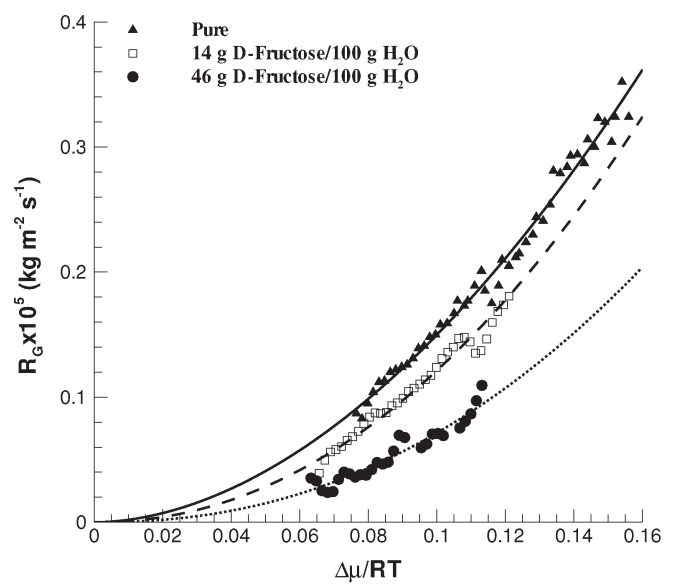

(a)

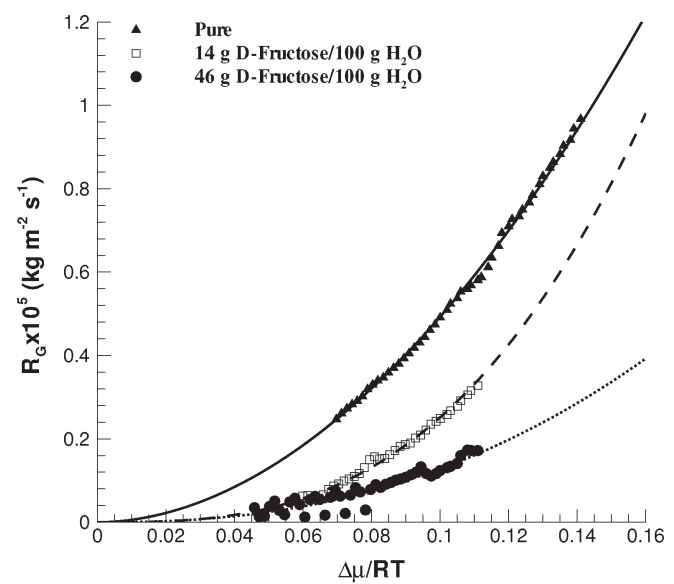

(b)

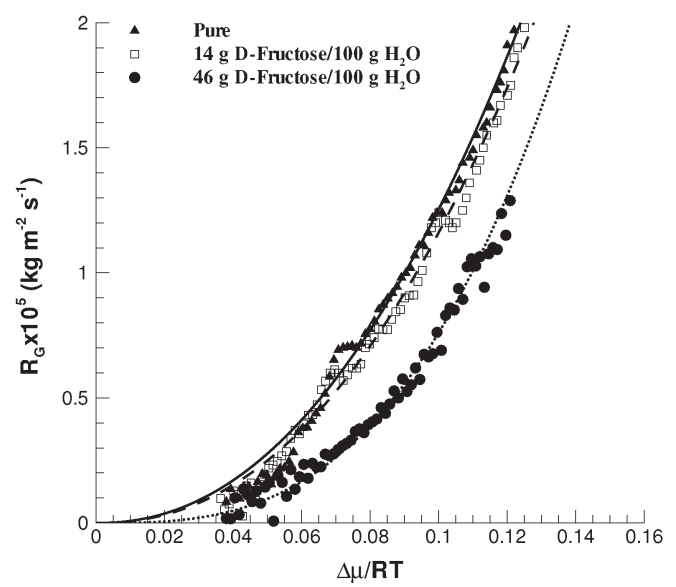

(c)

Figure 8. Growth rates of sucrose in pure mother liquors and in ternary solutions with D-fructose at $25{ }^{\circ} \mathrm{C}(\mathrm{a}), 35^{\circ} \mathrm{C}(\mathrm{b})$, and $50{ }^{\circ} \mathrm{C}(\mathrm{c})$.

where $R$ is the gas constant $(8.31432 \mathrm{~J} /(\mathrm{mol} \mathrm{K})), T$ is the temperature $(K)$, and $x_{\mathrm{i}}$ and $x_{\mathrm{i}}^{\text {sat }}$ are the mole fractions of component $i$ in supersaturated solution and in the saturated solution, respectively. $\gamma_{i}$ and $\gamma_{i}^{\text {sat }}$ are the activity coefficients of component $i$ in supersaturated solution and in the saturated solution, respectively. A modified UNIQUAC model with linear temperature-dependent parameters, proposed by Peres and Macedo, ${ }^{28}$ was used in order to obtain the $\gamma_{i}$ and $\gamma_{i}^{\text {sat }}$ coefficients.

Image Acquisition. Crystal images are acquired using a monochrome video digital camera (Sony, XCD-X700) located at the image analysis cell, Figure $1 \mathrm{c}$, where the solution flows at a constant rate $(200 \mathrm{~mL} / \mathrm{min})$. In order to study the peristaltic pump influence on the crystals, particularly their size and complexity, several measurements were performed using the pump before and after the cell, and no significant changes in results were verified. Thus, one can conclude that the crystal images taken at the cell describe well the crystals inside the crystallizer.

It must be pointed out that the bypass configuration presented can solve, also, the problem of the crystal content limitation reported by Martins et al. ${ }^{23}$ With the present apparatus, it is possible to decrease the crystal content inside the cell by adding saturated solution to the sample collected from the crystallizer. By this way, the image complexity decreases and the analysis can be done even when a high crystal content inside the crystallizer is present.

\section{MORPHOLOGY ASSESSMENT AND CLASSIFICATION}

Image Analysis. A sequence of images obtained from an image analysis cell is presented in Figure 2. These images (about 3 per second) are then treated and analyzed, and several numerical descriptors are extracted for each crystal using Visilog $\mathrm{Tm}^{5}$ (Noesis, les Ulis, France).

The image treatment consists of the following: reduction of the color depth of the image from 256 levels of gray to two colors (Figure 3a,b), hole filling (Figure 3b,c), noise elimination (Figure 3c,d), elimination of the objects that contact the board of the image (Figure 3d,e), and identification of the particles in the image (Figure $3 \mathrm{e}, \mathrm{f})$.

The 2D image descriptors are silhouette surface $S$ from which the equivalent diameter $\left(D_{\mathrm{eq}}=2(S / \pi)^{1 / 2}\right)$ is deduced, perimeter $P$, surface occupied by the internal zones $S_{\text {in }}$ number of internal zones $N_{\mathrm{i}}$ and Feret diameters distribution, from which the maximal $\left(F_{\max }\right)$ and minimal $\left(F_{\min }\right)$ are deduced (Figure 4$)$. These Feret diameters are calculated at different angles $\alpha$, the diameter being the distance between two parallel tangents to the silhouette and making an angle $\alpha$ with the vertical. $S_{\text {in }}$ and $N_{\mathrm{i}}$ are related to the 
Table 2. Parameters Obtained for the Growth Empirical Curves (eq 3) for the System Sucrose $/ \mathrm{H}_{2} \mathrm{O} / \mathrm{D}$-Fructose ${ }^{a}$

\begin{tabular}{cccc}
$T\left({ }^{\circ} \mathrm{C}\right)$ & $C_{\text {imp }}\left(\mathrm{g} / 100 \mathrm{~g} \mathrm{H}_{2} \mathrm{O}\right)$ & $k_{\mathrm{G}} \times 10^{4}$ & $g$ \\
25 & 0 & 1.12 & 1.87 \\
& 14 & 1.50 & 2.09 \\
& 46 & 1.22 & 2.23 \\
& 0 & 4.11 & 1.92 \\
& 14 & 19.76 & 2.90 \\
50 & 46 & 3.08 & 2.38 \\
& 0 & 18.87 & 2.18 \\
& 14 & 19.22 & 2.22 \\
& 46 & 72.39 & 2.98 \\
${ }^{a} k_{\mathrm{G}}$ is presented in $\mathrm{kg} \mathrm{m}^{-2} \mathrm{~s}^{-1}$. & & \\
\hline
\end{tabular}

central and transparent parts of the sucrose crystals (see Figure 3a,b). When the light is transmitted through the crystal, the beam is subject to phenomena of reflection and refraction at the crystal/ solution interfaces but also at the interfaces between two crystal planes in agglomerates. In the case of simple crystal, a unique zone with high gray levels is visible at the center of the crystal. In the case of agglomerates, many internal zones are noticeable.

From the previous parameters, a set of secondary parameters are calculated: ${ }^{14,29}(1)$ circularity $C=P^{2} /(4 \pi S)$; this parameter allows the elongation and roughness measurements of the object. It takes the value 1 for a circle and $4 / \pi$ for a square and is higher than $4 / \pi$ for a rectangle; (2) elongation $\left(F_{\max } / F_{\min }\right)$, specially important in sucrose crystallization, as the elongated shape is characteristic of these crystals. The influence of different impurities on this parameter has been studied over the years; ${ }^{14,30-32}(3)$ aspect ratio $\left(F_{\max } / D_{\mathrm{eq}}\right)$, reflects the circularity of the crystal. This parameter takes the value 1 for circular objects, $(\pi / 2)^{1 / 2}$ for square objects, and superior to $(\pi / 2)^{1 / 2}$ for rectangular objects; (4) $\operatorname{areas}_{\text {ratio }}\left(S / S_{\text {in }}\right)$, the ratio between the surface of the crystal and the surface occupied by the central and transparent part of the crystal; it tends to be larger for agglomerate crystals; (5) $\operatorname{box}_{\text {ratio }}\left(S_{\text {box }} / S\right)$, where $S_{\text {box }}=F_{\text {min }}(\alpha) \cdot F_{\text {min }}\left(\alpha+90^{\circ}\right)$. Normally, this parameter is higher for agglomerate crystal, as they do not fit well within the rectangular box; (6) the particle robustness $\Omega_{1}=2 w_{1} /(S)^{1 / 2}$, where $w_{1}$ is the number of erosions necessary for the object to disappear (Figure 5); (7) the index of largest concavity $\Omega_{2}=2 w_{2} /(S)^{1 / 2}$, where $w_{2}$ is the number of erosions necessary for concavities to disappear (Figure 5); (8) the ratio of the largest concavity to the total concavity $\left(\Omega_{3}\right)$.

Crystal Classification. Crystals are separated in three groups that should represent different (increasing) types of complexity. In the present work, as shown in Figure 6, such grouping results from a distinction between simple crystals and medium and large agglomerate crystals. The crystal size was not considered as a parameter in the crystal classification.

In order to obtain an automated classification of the crystals, the discriminant factorial analysis (DFA) method was trained, using the parameters obtained from the image analysis applied to a population test of 1000 crystals visually classified by an operator, according to Figure 6. These crystals were obtained during the crystallization process at different supersaturations. According to Faria et al., ${ }^{14}$ a minimum of 500 particles should be analyzed to ensure a confidence interval smaller than $5 \%$ for $D_{\text {eq }}$ and $2 \%$ for the shape descriptors and an acceptable stability of the coefficients of variation, i.e., of the parameter distributions. The method performs the distinction among simple crystals, medium

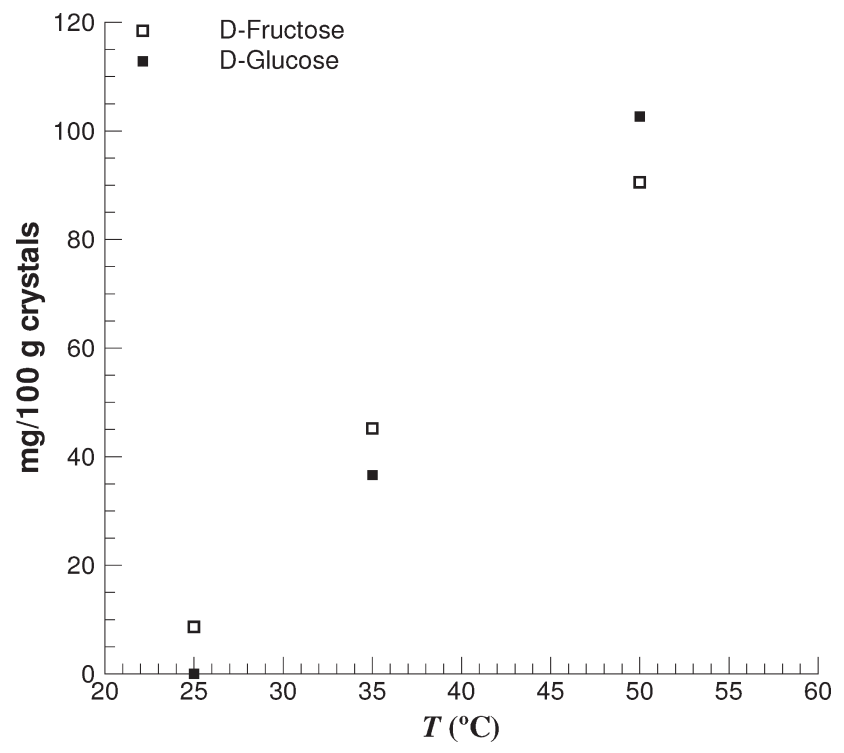

Figure 9. Impurity adsorption into the crystals at different temperatures (systems with $46 \mathrm{~g}$ of impurity/100 $\mathrm{g} \mathrm{H}_{2} \mathrm{O}$ ).

agglomerates, and large agglomerates. A statistical toolbox, XLstat (T. Fahmy, Paris, France), running under Excel (Microsoft) was used for that purpose. The software calculates the characteristics of each group in terms of its centroid and variance radius. The operator does not have to define numerically the limits of each group in terms of descriptor values. The distance of crystal parameters to the centroid characterizes the probability for a crystal $i$ to belong to the group $j\left(\mathrm{~Pb}_{\mathrm{i}, \mathrm{j}}\right)$ and is used as classification criterion. Each crystal is assigned to the group for which the probability is the highest.

The degree of mismatch between the automated and visual classifications is evaluated by the following performance index

$$
\mathrm{PI}(\%)=\left(1-\frac{\text { number of misclassified crystals }}{\text { total number of crystals }}\right) \times 100
$$

As the automatic classification is based on the probability of each crystal belonging to each of the considered groups, it is possible to determine the complexity of the crystal through the parameter agglomeration degree of the crystal $\left(\mathrm{Ag}_{\mathrm{i}}\right) .{ }^{14}$ In present work, this parameter was calculated through the following equation:

$$
\mathrm{Ag}_{\mathrm{i}}=100\left(\mathrm{~Pb}_{\mathrm{i}, \mathrm{S}}+\frac{3}{2} \mathrm{~Pb}_{\mathrm{i}, \mathrm{MA}}+2 \mathrm{~Pb}_{\mathrm{i}, \mathrm{VA}}-1\right)
$$

where $\mathrm{Pb}_{\mathrm{i}, \mathrm{S}}, \mathrm{Pb}_{\mathrm{i}, \mathrm{MA}}$, and $\mathrm{Pb}_{\mathrm{i}, \mathrm{VA}}$ are the probabilities of each crystal being a simple, medium agglomerate, and large agglomerate crystal, respectively. This relation is a linear combination of the three probabilities calculated so that

$$
\begin{aligned}
& \mathrm{Pb}_{\mathrm{i}, \mathrm{S}}=1 \Longrightarrow \mathrm{Ag}_{\mathrm{i}}=0 \% \\
& \mathrm{~Pb}_{\mathrm{i}, \mathrm{MA}}=1 \Longrightarrow \mathrm{Ag}_{\mathrm{i}}=50 \% \\
& \mathrm{~Pb}_{\mathrm{i}, \mathrm{VA}}=1 \Longrightarrow \mathrm{Ag}_{\mathrm{i}}=100 \%
\end{aligned}
$$

\section{RESULTS AND DISCUSSION}

The experimental procedures previously described were used to evaluate the influence of $\mathrm{CaCl}_{2}$, D-fructose, and D-glucose in the crystallization of sucrose, namely, on crystal growth rate and 


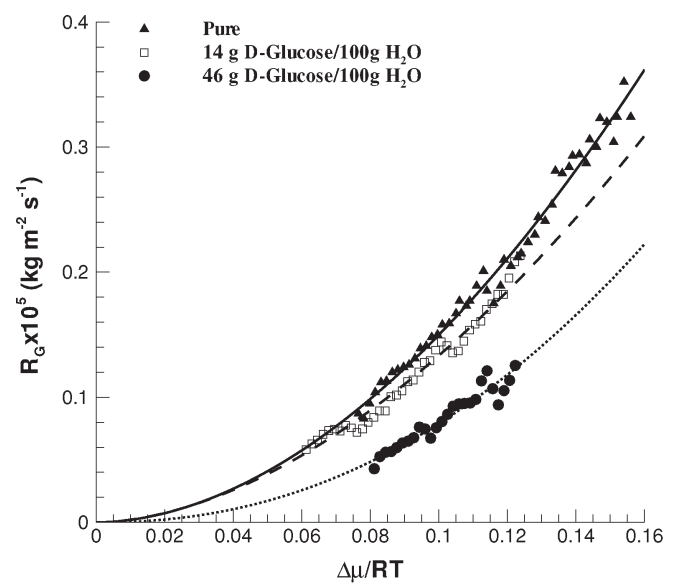

(a)

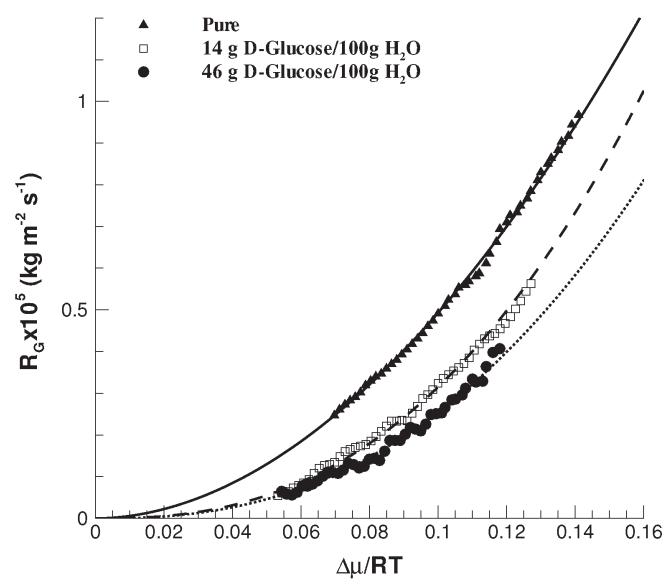

(b)

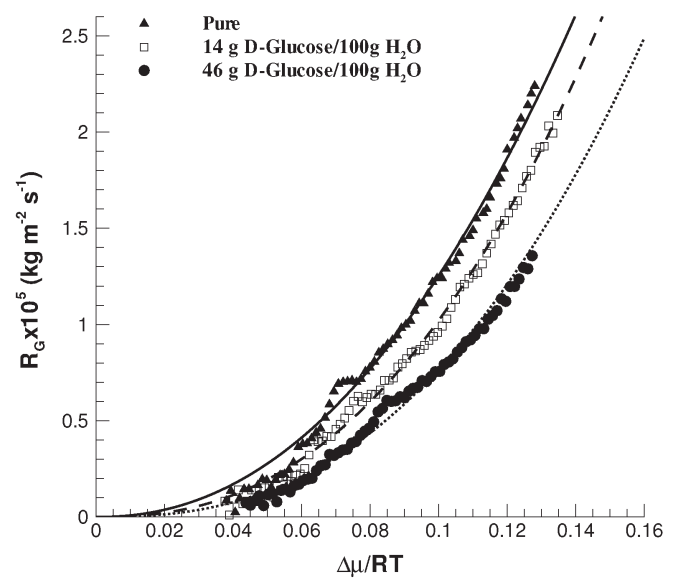

(c)

Figure 10. Growth rates of sucrose in pure mother liquors and in ternary solutions with D-glucose at $25{ }^{\circ} \mathrm{C}(\mathrm{a}), 35^{\circ} \mathrm{C}(\mathrm{b})$, and $50{ }^{\circ} \mathrm{C}(\mathrm{c})$.

agglomeration degree. The impurity adsorption into the crystals at different temperatures was also studied. For that, potentiometric titration and high-performance liquid chromatography (HPLC) were used in order to quantify $\mathrm{CaCl}_{2}{ }^{33}$ and D-fructose and D-glucose, respectively. For the HPLC analysis, the column LiChospher $100 \mathrm{NH}_{2}, 5 \mu \mathrm{m}$, and the detector ELSD-Sedex Model 55-SEDERE (Alfortville, France) were used. The mobile phase used was a mixture of acetonitrile $/ \mathrm{H}_{2} \mathrm{O} 80: 20 \mathrm{v} / \mathrm{v}$. This mixture was degassed with helium (99.995\% purity) for $15 \mathrm{~min}$, just before use.

Crystal Growth Rate. In this section, the experimental results related to the impurities influence on overall growth rate are presented.

$\mathrm{CaCl}_{2} \cdot \mathrm{CaCl}_{2}$ influence on sucrose crystallization has been studied by different authors. Smythe ${ }^{9}$ concluded, in experiments done at $41^{\circ} \mathrm{C}$, that an impurity concentration above $15 \mathrm{~g} \mathrm{CaCl}_{2} /$ $100 \mathrm{~g} \mathrm{H}_{2} \mathrm{O}$ decreases the growth rate. On the other hand, Mantovani et al. ${ }^{15}$ observed an influence on growth rate, for impurity concentrations above $5 \mathrm{~g} \mathrm{CaCl}_{2} / 100 \mathrm{~g} \mathrm{H}_{2} \mathrm{O}$. In the present work, impurity concentrations up to $10 \mathrm{~g} \mathrm{CaCl}_{2} / 100 \mathrm{~g}$ $\mathrm{H}_{2} \mathrm{O}$ were studied. In Figure 7, the growth rates obtained at different temperatures are presented. The parameters of eq 3 that best fit the experimental results are presented in Table 1.
According to the results, the growth rates seem to decrease in the presence of this impurity, mainly at low temperatures. This effect increases with impurity concentration. The impurity influence on growth rate seems to be related to the integration process, as the impurity, according to dissolutions results (presented in Ferreira et al. ${ }^{33}$ ), slightly increases the diffusion coefficient of sucrose in solution. The impurity concentration obtained in the crystals, at the end of the experiments, was 3.63 and $4.36 \mathrm{mg} \mathrm{CaCl} / 2 / 100 \mathrm{~g}$ crystals at 25 and $50{ }^{\circ} \mathrm{C}$, respectively, for the impurity concentration in solution of $3 \mathrm{~g} / 100 \mathrm{~g} \mathrm{H}_{2} \mathrm{O}$, and 5.79 and $6.94 \mathrm{mg} \mathrm{CaCl}_{2} / 100 \mathrm{~g}$ crystals at 25 and $50{ }^{\circ} \mathrm{C}$, respectively, for the impurity concentration in solution of 10 $\mathrm{g} / 100 \mathrm{~g} \mathrm{H}_{2} \mathrm{O}$. The adsorption results indicate that the impurity adsorption increases with temperature and impurity concentration, a phenomenon predicted by Ferreira et al. ${ }^{33}$

D-Fructose. As previously reported, the individual influence of D-fructose and D-glucose on sucrose crystallization is, mainly, focused on crystal morphology change. ${ }^{4-7}$ The sucrose growth rates in the presence of these impurities are usually found in the literature not as an individual influence of these two monosaccharides but as a collective influence of invert sugar (an equimolar mixture of D-fructose and D-glucose $).^{8-14}$ Some exceptions can be found in the literature, as in Martins et al. ${ }^{34}$ work. These 
Table 3. Parameters Obtained for the Growth Empirical Curves (eq 3) for the System Sucrose $/ \mathrm{H}_{2} \mathrm{O} / \mathrm{D}$-Glucose ${ }^{a}$

\begin{tabular}{cccc}
$T\left({ }^{\circ} \mathrm{C}\right)$ & $\mathrm{C}_{\text {imp }}\left(\mathrm{g} / 100 \mathrm{~g} \mathrm{H}_{2} \mathrm{O}\right)$ & $k_{\mathrm{G}} \times 10^{4}$ & $\mathrm{~g}$ \\
25 & 0 & 1.12 & 1.87 \\
& 14 & 0.82 & 1.79 \\
& 46 & 1.25 & 2.20 \\
& 0 & 4.11 & 1.92 \\
& 14 & 10.19 & 2.51 \\
50 & 46 & 7.42 & 2.46 \\
& 0 & 18.87 & 2.18 \\
& 14 & 25.13 & 2.39 \\
& 46 & 24.81 & 2.51 \\
${ }^{a} k_{\mathrm{G}}$ is presented in $\mathrm{kg} \mathrm{m}^{-2} \mathrm{~s}^{-1}$. & & \\
\hline
\end{tabular}

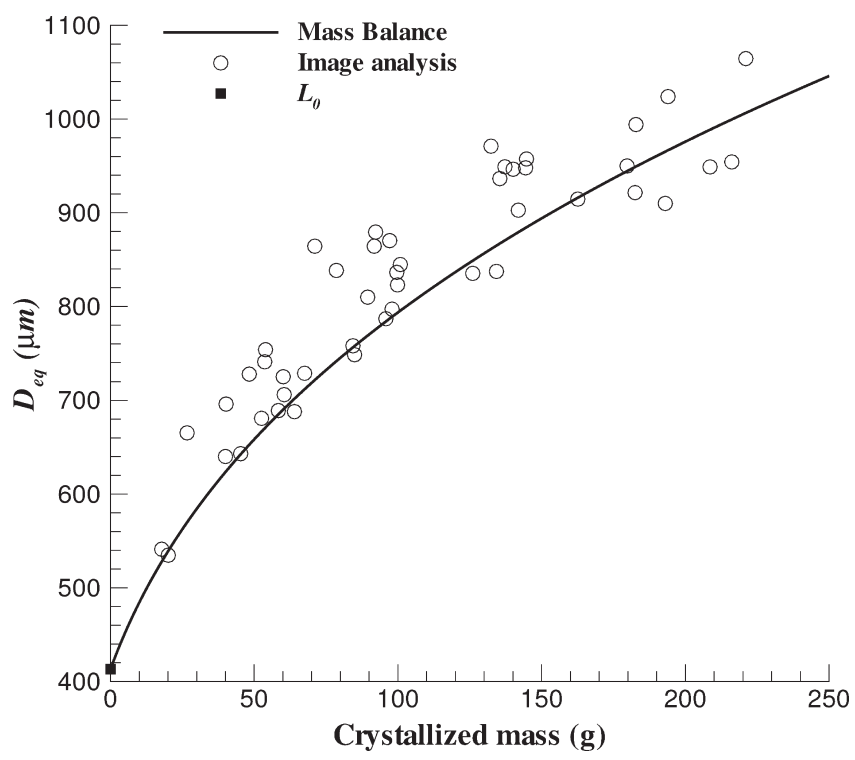

Figure 11. Comparison between the mean equivalent diameters obtained by the image analysis method and by the mass balance method.

authors studied the D-fructose influence on sucrose growth rate in industrial syrups and concluded that D-fructose has a strong impact on growth rate. In the present work, the two monosaccharides were studied individually, in order to understand their influence on growth rates and crystal complexity. The effect of increasing fructose concentrations toward the inhibition of the crystal growth rate of sucrose is shown in Figure 8. The parameters of eq 3 that best fit the experimental results are presented in Table 2 .

As one can see, the impurity has a remarkable influence on growth kinetics. It can also be observed, for all temperatures, that the growth rate decreases when impurity concentration increases. These results are in agreement with McGinnis, ${ }^{12}$ Webster, ${ }^{13}$ and Martins et al..$^{34}$ conclusions. The previous results seem to be related to the integration process, as the influences observed on growth rate are higher than the ones observed on dissolution rate (not presented). The high values obtained for $g$ indicate the possible existence of a critical supersaturation, below which crystal growth ceases, a behavior predicted by classic pinning mechanisms. ${ }^{35,36}$ The impurity adsorption into the crystals at different temperatures is presented in Figure 9. As one can see, the impurity adsorption increases linearly with the temperature. Combining these results

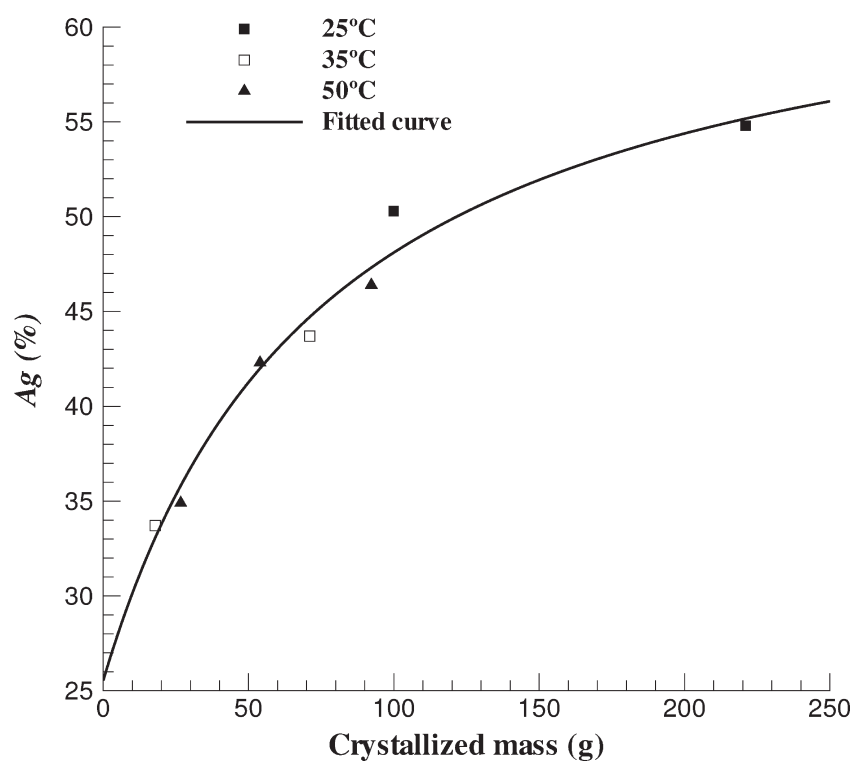

Figure 12. Temperature effect on mean agglomeration degree of a crystal population (pure system).

with the growth rate results, we can infer that the impurity adsorption increases with the growth rate. This conclusion is in agreement with the Ferreira et al. ${ }^{33}$ work.

D-Glucose. In Figure 10, the growth rates obtained, at different temperatures, in pure and impure systems with D-glucose are presented. The parameters of eq 3 that best fit the experimental results are presented in Table 3.

As one can see, the D-glucose influence on sucrose crystal growth rate is very similar to D-fructose; however, it seems that this last monosaccharide has a higher influence. This conclusion is in agreement with several works ${ }^{6,7}$ that emphasize the idea that these monosaccharides have different adsorption mechanisms resulting in different growth rate influences. According to Figure 9, it seems that the affinity of D-glucose and D-fructose to the crystal is similar. Thus, the higher influence on growth rate observed in D-fructose systems is probably related, beyond different adsorption mechanisms, to the face selectivity, resulting by this way in different crystal shapes.

Crystal Complexity. The crystal complexity study begins with the automatic classification of each crystal according to the tree presented in Figure 6. The performance indexes obtained for the population test were as follows: simple crystals, $85 \%$; medium agglomerate crystals, $45 \%$; and large agglomerate crystals, $80 \%$. As one can see, the performance indexes for the distinction between simple crystals and large agglomerate crystals are very high, showing a high agreement between the automated and visual classifications. However, the automatic classification of medium agglomerate crystals is not so good, as a result of the higher subjectivity level of this classification. The same problem was reported by Faria et al., ${ }^{14}$ Faria, ${ }^{37}$ and Ferreira et al. ${ }^{18}$ Comparing the present online classification with off-line classification reported by Faria et al. ${ }^{14}$ and Faria ${ }^{37}$ (PI $=94 \%$ simple crystals, $45 \%$ medium agglomerates, and 50\% large agglomerates), one can conclude that, globally, the present online image analysis gives better results. The time required for the image analysis technique with statistical meaning is about $1 \mathrm{~min}$ for crystal size measurements and less than $10 \mathrm{~min}$ for population classification. 


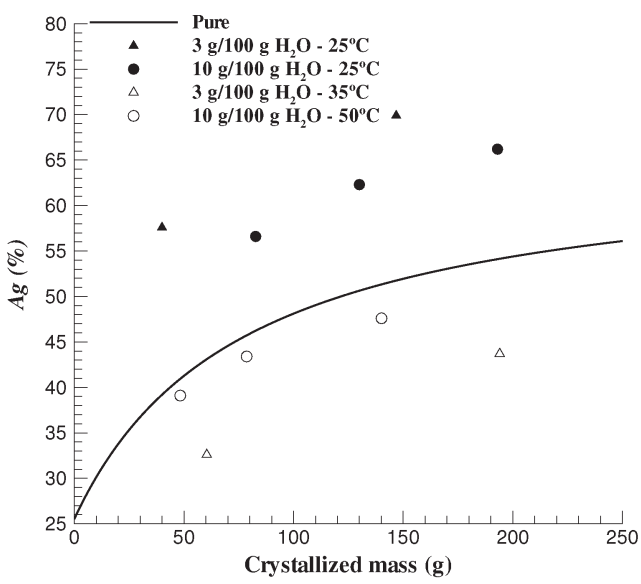

(a)

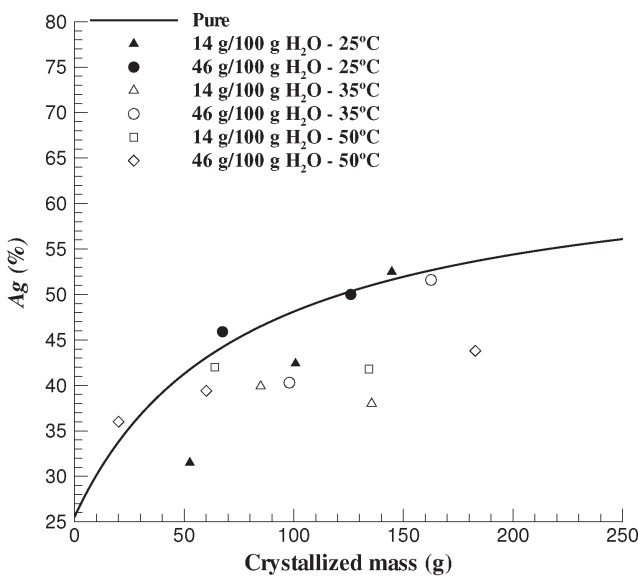

(b)

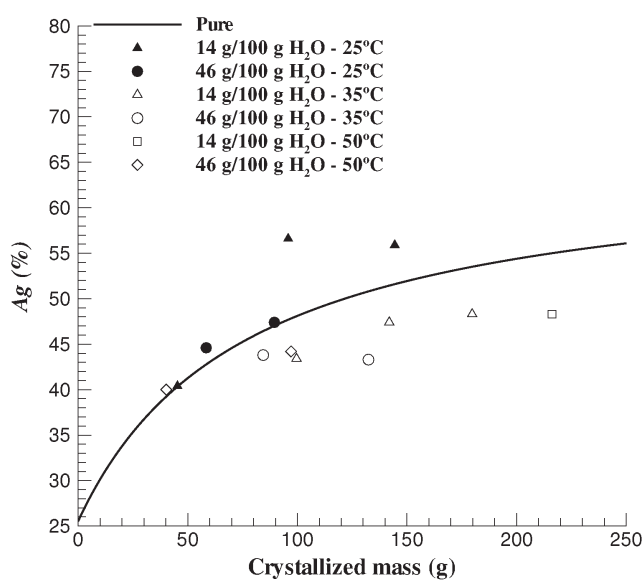

(c)

Figure 13. Evolution of the mean agglomeration degree in the system sucrose $/ \mathrm{H}_{2} \mathrm{O} /$ impurity at 25,35 , and $50{ }^{\circ} \mathrm{C}$. (a) CaCl ${ }_{2}$; (b) $\mathrm{D}$-fructose; (c) D-glucose.

To study the effect of supersaturation, growth rate, and impurity concentration on the type, amount, and complexity level of the agglomerates, the image analysis results were combined with the growth rate results, expecting with this study to open new insights for a better understanding of crystallization phenomena. A comparison between the mean equivalent diameters obtained by the image analysis method and by the mass balance method is presented in Figure 11. As one can see, a good agreement between the methods was obtained. Thus, one can conclude that the results obtained from the online application of an image analysis technique are reliable.

Pure System. In Figure 12, the evolution of population complexity, in a pure system, during a run, for different temperatures is presented.

As one can see, the population complexity increases with the crystallized mass and seems not to be affected by the temperature. Combining these results with the growth rates shown previously at different temperatures, it can be inferred that the growth rate is not a variable with high influence on population complexity. It seems that the mass of crystals is the variable with higher impact on crystal complexity. These results are not directly in agreement with Ferreira et al. ${ }^{18}$ conclusions.
According to the authors, the agglomeration degree increases with growth rate. However, as the experiments were done in a fluidized bed crystallizer for different supersaturation values, the samples, collected after the same crystallization time, had different mass. Thus, one can infer, from the results obtained in the present work, that the variable that influences the agglomeration degree in the Ferreira et al. ${ }^{18}$ work is not the growth rate but the crystal content (mass of crystals per solution volume) present in the fluidized bed. The present results are also in agreement with Faria et al. ${ }^{14}$ which conclude that agglomeration degree increases with equivalent diameter. As these experiments were done in a batch crystallizer and the nucleation was assumed not to occur, the equivalent diameter is directly related to crystal mass.

The mean agglomeration degree of the entire population, $\mathrm{Ag}$, was related to the crystallized mass, $m_{\mathcal{c}}$, according to the following equation:

$$
\mathrm{Ag}(\%)=\frac{0.519 m_{\mathrm{c}}}{1+0.013 m_{\mathrm{c}}}+\mathrm{Ag}_{\mathrm{s}}
$$

where $\mathrm{Ag}_{\mathrm{s}}$ is the mean agglomeration degree of the seeds, that takes the value $25.5 \%$. This equation, obtained for pure system, 


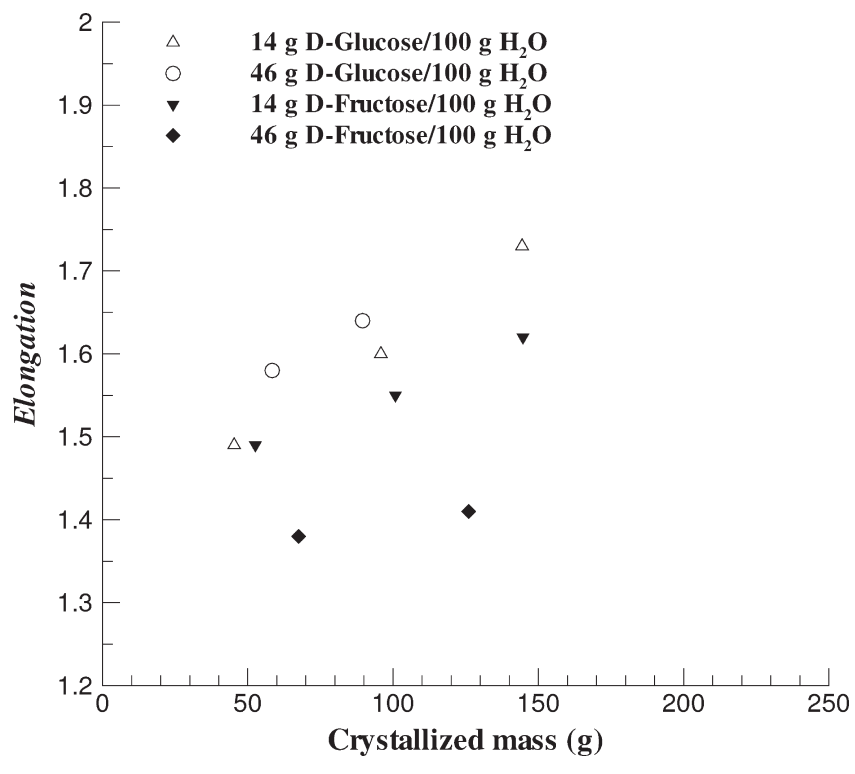

Figure 14. Evolution of the crystal elongation in the systems sucrose/ $\mathrm{H}_{2} \mathrm{O} / \mathrm{D}$-glucose and D-fructose at $25^{\circ} \mathrm{C}$.

was used as reference for the study of the impurity influence on crystal complexity.

Impure Systems. The experimental results obtained in the presence of different impurities are summarized in Figure 13. Globally, the agglomeration degree increases with crystallized mass, as seen before for pure systems. However, in the present case, crystal growth in the presence of impurities, the phenomenon is more complex. According to Figure 13a, we can observe that, at $25{ }^{\circ} \mathrm{C}, \mathrm{CaCl}_{2}$ increases the crystal complexity in comparison with the pure system. This effect is more significant for the lower impurity concentration. Comparing these results with growth rate curves obtained in an impure system (see Figure 7), it seems that this behavior is related to growth rate, i.e., low growth rates lead to low crystal complexities. Thus, as temperature increases, it would be expected that crystal complexity increases. However, this does not happen, suggesting that growth rate is not the more adequate variable to correlate the crystal population complexity. This conclusion supports the previous one obtained for pure systems.

In what concerns the sucrose $/ \mathrm{H}_{2} \mathrm{O} / \mathrm{D}$-fructose and D-glucose systems, Figure 13b,c, respectively, we can observe that, unless for the D-glucose system at $25{ }^{\circ} \mathrm{C}$ and low concentration, the values of population complexity are similar or less than for pure systems. It seems, also, that $\mathrm{D}$-fructose presents a smaller influence on crystal agglomeration evolution. As the growth rates obtained for both monosaccharides are similar, the obtained results may be related to the specificity of $\mathrm{D}$-fructose and D-glucose on crystal shape change ${ }^{5-7}$ and, by this way, to affect the calculation of the crystal population complexity. From the image analysis results, it is possible to follow the crystal elongation during the crystallization process (Figure 14). According to the results, crystals grown in the presence of D-glucose present a higher elongation and the impurity concentration increase seems to not affect the crystal elongation evolution. On the other hand, the $\mathrm{D}$-fructose presence decreases the crystal elongation and this effect increases with the impurity concentration. Indeed, for high levels of impurity ( $46 \mathrm{~g} / 100 \mathrm{~g}$ water), it seems that the crystal growth slows down in one direction. Vaccari et al. ${ }^{5}$ showed that
D-glucose and D-fructose affect the habit of sucrose only when their concentrations are higher than $50 \mathrm{~g} / 100 \mathrm{~g}$ water and that the effects increase with the impurity concentration. These authors noted that glucose slows down the growth rate of the left pole forms, until blocking the $\{1 \overline{1} 0\}$ forms, and fructose strongly decreases the kinetics of the right pole forms, particularly the $\{011\}$ and $\{111\}$ forms but without stopping the growth of any form. Recently, Ouiazzane et al..$^{38}$ studied the influence of these two monosaccharides, with a concentration of $9.5 \mathrm{~g} / 100 \mathrm{~g}$ of water, on the sucrose crystals habit, and they found that both, and their combination, reduce the faces of sucrose crystals. The previous works explain the present results, specially the differences observed on growth rate and elongation using both monosaccharides and, also, corroborate the idea that the specificity of D-fructose on crystal shape can explain the higher impact of this monosaccharide on crystal complexity.

\section{- CONCLUSIONS}

The goal of the present work is to develop a tool for online quantification of crystal complexity, eliminating, by this way, the problems related with sample collection, characteristic of off-line analysis. This development aims to open new insights for a better understanding of crystallization phenomena. This was achieved by combining an image analysis technique, based on online image acquisition, with discriminant factorial analysis, using an image analysis cell purposely designed. The association of these techniques enabled the online quantification of the population complexity level during a crystallization run. The agreement between the automated and visual classification, for simple and large agglomerate crystals, was about $83 \%$, while for medium agglomerates the classification was not so good (45\%). The time required for the image analysis technique with statistical meaning was less than $1 \mathrm{~min}$ for crystal size measurements and $10 \mathrm{~min}$ for population classification.

The experimental results point out that population complexity depends directly on crystallized mass instead of crystal growth rate. The impurities have a significant influence on crystal complexity. $\mathrm{CaCl}_{2}$ increases the complexity of the crystals at $25^{\circ} \mathrm{C}$, in comparison with the pure systems. This effect is more significant for low impurity concentrations. For the other temperatures, the impurity decreases the complexity of the crystals. Regarding the $\mathrm{D}$-fructose and D-glucose impurities, for the range of temperatures studied and except for the D-glucose system at $25^{\circ} \mathrm{C}$ and low concentration, the values of population complexity are similar or less than for pure systems. D-Fructose seems to have a higher influence on the agglomeration degree. With the crystal growth rates being similar, this effect is possibly related to the specificity of these two monosaccharides on sucrose crystal. The elongation results corroborate this idea, as different elongated crystals were obtained. Crystals grown in the presence of D-glucose are more elongated. These results are in agreement with the literature.

In short, the results suggest that the mechanisms governing the agglomeration of sucrose crystals in the presence of impurities are different than those occurring in pure systems. It seems that crystal elongation can affect the crystal complexity. Combining the results of impurity adsorption, image analysis, and crystal growth rate, it was possible to understand better the crystallization phenomena in the presence and absence of impurities. The results presented in this work show the potential applicability of the developed image analysis methodology to monitor and control the crystallization process. 


\section{AUTHOR INFORMATION}

\section{Corresponding Author}

*E-mail: frocha@fe.up.pt. Phone: + 351 225081678. Fax: + 351 225081632.

\section{ACKNOWLEDGMENT}

This work was supported by Fundação para a Ciência e Tecnologia under program contract numbers SFRH/BD/11315/2002 and SFRH/BPD/45637/2008.

\section{- LIST OF SYMBOLS}

$\mathrm{Ag}=$ mean agglomeration degree of the entire population

$\mathrm{Ag}_{\mathrm{i}}=$ agglomeration degree of the crystal $i$

$\mathrm{Ag}_{\mathrm{s}}=$ mean agglomeration degree of the seeds

$C=$ circularity

$D_{\text {eq }}=$ equivalent diameter $(\mathrm{m})$

$F_{\text {max }}=$ maximal Feret diameters $(\mathrm{m})$

$F_{\min }=$ minimal Feret diameters $(\mathrm{m})$

$F_{\min }\left(\alpha+90^{\circ}\right)=$ Feret diameter perpendicular to $F_{\min }$

$g=$ overall growth

$k_{\mathrm{G}}=$ growth rate constant $\left(\mathrm{kg} \mathrm{m}^{-2} \mathrm{~s}^{-1}\right)$

$L_{0}=$ seed mean size $(\mathrm{m})$

$m=$ mass of crystals $(\mathrm{kg})$

$m_{\mathrm{c}}=$ crystallized mass $(\mathrm{kg})$

$m_{\mathrm{t}}=$ mass of crystals at time $t(\mathrm{~kg})$

$m_{\mathrm{t}+\Delta \mathrm{t}}=$ mass of crystals at time $t+\Delta t(\mathrm{~kg})$

$m_{0}=$ initial mass of crystals $(\mathrm{kg})$

$N=$ number of crystals

$N_{\mathrm{i}}=$ number of internal zones

$P=$ Crofton perimeter $(\mathrm{m})$

$\mathrm{PI}=$ performance index

$\mathrm{Pb}_{\mathrm{i}, \mathrm{S}}=$ probability of crystal being simple

$\mathrm{Pb}_{\mathrm{i}, \mathrm{MA}}=$ probability of crystal being medium agglomerate

$\mathrm{Pb}_{\mathrm{i}, \mathrm{VA}}=$ probability of crystal being large agglomerate

$R=$ gas constant $(\mathrm{J} /(\mathrm{mol} \mathrm{K}))$

$R_{\mathrm{g}}=$ crystal growth rate $\left(\mathrm{kg} \mathrm{m}^{-2} \mathrm{~s}^{-1}\right)$

$S=$ projected surface area $\left(\mathrm{m}^{2}\right)$

$S_{\text {in }}=$ surface occupied by the transparent zones $\left(\mathrm{m}^{2}\right)$

$\mathrm{T}=$ temperature $\left({ }^{\circ} \mathrm{C}\right.$ or $\left.\mathrm{K}\right)$

$t=$ time $(\mathrm{s})$

$w_{1}=$ number of erosions necessary for object to disappear

$w_{2}=$ number of erosions necessary for concavities to disappear

$x_{\mathrm{i}}=$ mole fraction of component $i$ in supersaturated solution

$x_{\mathrm{i}}^{\text {sat }}=$ mole fraction of component $i$ in saturated solution

$\alpha=$ angle $\left(^{\circ}\right)$

$\alpha=$ volume shape factor

$\beta=$ surface shape factor

$\Delta t=$ time interval $(\mathrm{s})$

$\gamma_{\mathrm{i}}=$ activity coefficient of component $i$ in supersaturated solution

$\gamma_{i}^{\text {sat }}=$ activity coefficient of component $i$ in saturated solution

$\rho_{\mathrm{c}}=$ sucrose density $\left(\mathrm{kg} \mathrm{m}^{-3}\right)$

$\Omega_{1}=$ particle robustness

$\Omega_{2}=$ largest concavity index

$\Omega_{3}=$ concavity ratio

$((\Delta \mu) /(\mathrm{RT}))=$ thermodynamic driving force of crystallization

\section{REFERENCES}

(1) Sangwal, K. Additives and Crystallization Processes: From Fundamentals to Applications; Wiley: Chichester,WestSussex, 2007.
(2) Yu, Z.; Chew, J.; Chow, P.; Tan, R. Recent Advances in Crystallization control: An Industrial Perspective. Chem. Eng. Res. Des. 2007, 85, 893-905.

(3) Sangwal, K. Effects of impurities on crystal growth processes. Prog. Cryst. Growth Charact. Mater. 1996, 32, 3-43.

(4) Hook, A. V. Habit Modifications of Sucrose Crystal. J. Am. Soc. Sugar Beet Technol. 1983, 22, 60.

(5) Vaccari, G.; Mantovani, G.; Sgualdino, G.; Zefiro, L. Effect of Glucose and Fructose on Cane Sugar Crystal Morphology. Zuckerindustrie 1991, 116, 610 .

(6) Bubnik, Z.; Vaccari, G.; Mantovani, G.; Sgualdino, G.; Kadlec, P. Effect of Dextran, Glucose and Fructose on Sucrose Crystal Elongation and Morphology. Zuckerindustrie 1992, 117, 557.

(7) Sgualdino, G.; Aquilano, D.; Vaccari, G.; Mantovani, G.; Salamone, A. Growth Morphology of Sucrose Crystals. The Role of Glucose and Fructose as Habit-Modifiers. J. Cryst. Growth 1998, 192, 290.

(8) Chen, J. C. P. Meade-Chen Cane Sugar Handbook, 11th ed.; John Wiley \& Sons: New York, 1985.

(9) Smythe, B. M. Sucrose Crystal Growth. II. Rate of Crystal Growth in Presence of Impurities. Aust. J. Chem. 1967, 20, 1097-1114.

(10) Hook, A. V. Kinetic of Sucrose Crystallization. Real Massecuites. Ind. Eng. Chem. 1948, 40, 85-89.

(11) Hook, A. V. Sucrose Crystallization Mechanism of Growth from Aqueous Solution. J. Cryst. Growth 1969, 5, 305-311.

(12) McGinnis, R. A. Exhaustion of Beet Molasses. Sugar Technol. Rev. 1978, 5, 155-286.

(13) Webster, G. Sucrose Crystal Growth Kinetics Using a Rotating Disc. Ph.D. thesis, Manchester University, Manchester, UK, 1988.

(14) Faria, N.; Pons, M. N.; Feyo de Azevedo, S.; Rocha, F. A.; Vivier, H. Quantification of the Morphology of Sucrose Crystals by Image Analysis. Powder Technol. 2003, 133, 54-67.

(15) Mantovani, G.; Fagioli, F.; Accorsi, C. Die Auflösung Von Saccharose in Gegenwart Von Nichtzuckerstoffen. Zuckerindustrie 1968, $21,70-74$.

(16) Feyo de Azevedo, S.; Rocha, F.; Faria, N.; Pons, M. N. Using Image Analysis to Look Into the Effect of Operating Conditions in Sugar Crystallisation. Proceedings of the 15th International Symposium on Industrial Crystallization, AIDIC: Sorrento, 2002, 1377-1382.

(17) Faria, N.; Feyo de Azevedo, S.; Rocha, F.; Pons, M. Modelling Agglomeration Degree in Sucrose Crystallisation. Chem. Eng. Process. 2008, 47, 1666-1677.

(18) Ferreira, A.; Faria, N.; Rocha, F.; Feyo de Azevedo, S.; Lopes, A. Using Image Analysis to Look Into the Effect of Impurity Concentration in $\mathrm{NaCl}$ Crystallization. Chem. Eng. Res. Des. 2005, 83, 331-338.

(19) Lionnet, G. An Interfacial Model for the Transfer of Impurities Into the Sucrose Crystal. Chem. Eng. Res. Des. 1998, 76, 803-808.

(20) Monnier, O.; Fevotte, G.; Hoff, C.; Klein, J. P. Model Identification of Batch Cooling Crystallizations Through Calorimetry and Image Analysis. Chem. Eng. Sci. 1997, 52, 1125-1139.

(21) Calderon De Anda, J.; Wang, X.; Roberts, K. Multiscale segmentation image analysis for the in-process monitoring of particle shape with batch crystallisers. Chem. Eng. Sci. 2005, 60, 10531065.

(22) Calderon De Anda, J.; Wang, X.; Lai, X.; Roberts, K. Classifying organic crystals via in-process image analysis and the use of monitoring charts to follow polymorphic and morphological changes. J. Process Control 2005, 15, 785-797.

(23) Martins, P. M.; Rocha, F. A.; Rein, P. Modeling Sucrose Evaporative Crystallization. Part 1. Vacuum Pan Monitoring by Mass Balance and Image Analysis Methods. Ind. Eng. Chem. Res. 2005, $44,8858-8864$.

(24) Ferreira, A.; Faria, N.; Rocha, F. Roughness Effect on the Overall Growth Rate of Sucrose Crystals. J. Cryst. Growth 2008, 310, 442-451.

(25) Martins, P.; Rocha, F. The Role of Diffusional Resistance on Crystal Growth: Interpretation of Dissolution and Growth Rate Data. Chem. Eng. Sci. 2006, 61, 5686-5695. 
(26) Guimarães, L.; Sá, S.; Bento, L. S. M.; Rocha, F. Investigation of Crystal Growth in a Laboratory Fluidized Bed. Int. Sugar J. 1995, 97, 199-204.

(27) Bubnik, Z.; Kadlec, P. Sucrose Crystal Shape Factors. Zuckerindustrie 1992, 117, 345-350.

(28) Peres, A. M.; Macedo, E. A. Thermodynamic Properties of Sugars in Aqueous Solutions: Correlation and Prediction Using a Modified UNIQUAC Model. Fluid Phase Equilib. 1996, 123, 71-95.

(29) Pons, M. N.; Vivier, H.; Dodds, J. Particle Shape Characterization Using Morphological Descriptors. Part. Part. Syst. Charact. 1997, 14, 272-277.

(30) Pautrat, C.; Génotelle, J.; Mathlouthi, M. Sucrose Crystal Growth: Effect of Supersaturation, Size and Macromolecular Impurities. In Sucrose Crystallization. Science and Technology; VanHook et al., Eds.; Bartens, 1997, 57-70.

(31) Chorão, J. M. M. N. Operação Assistida Por Computador de Um Cristalizador Evaporativo Industrial de Açúcar. Ph.D. thesis, Faculdade de Engenharia da Universidade do Porto, Rua Dr. Roberto Frias, s/n 4200-465 Porto, PORTUGAL, 1995.

(32) Saska, M.; Polack, J. Effects of Dextran on Sucrose Crystal Shape. Proceedings of the 1982 Conference on Sugar Processing Research, Atlanta, GA, 1982, 134-142.

(33) Ferreira, A.; Faria, N.; Rocha, F. The Effect of Crystal Surface Roughness on Impurity Adsorption. Cryst. Res. Technol. 2009, 44, 521-533.

(34) Martins, P.; Ferreira, A.; Polanco, S; Rocha, F; Damas, A.; Rein, P Unsteady-State Transfer of Impurities During Crystal Growth of Sucrose in Sugarcane Solutions. J. Cryst. Growth 2009, 311, 3841-3848.

(35) Kubota, N.; Mullin, J. A Kinetic Model for Crystal Growth from Aqueous Solution in the Presence of Impurity. J. Cryst. Growth 1995, 152, 203-208.

(36) Cabrera, N.; Vermilyea, D. A. The Growth of Crystals from Solution. In Growth and Perfection of Crystals; Doremus, R. H., Roperts, B. W., Turnbull, D., Eds.; Wiley: New York, 1958, 393-410.

(37) Faria, N. Quantificação Da Morfologia de Cristais de Açúcar e Sua Aplicação Ao Estudo Das Cinéticas de Cristalização. Ph.D. thesis, Faculdade de Engenharia da Universidade do Porto, Rua Dr. Roberto Frias, s/n 4200-465 Porto, PORTUGAL, 2001.

(38) Ouiazzane, S.; Messnaoui, B.; Abderafi, S.; Wouters, J.; Bounahmidi, T. Modeling of Sucrose Crystallization Kinetics: The Influence of Glucose and Fructose. J. Cryst. Growth 2008, 310, 3498-3503. 